 \\ constructos identitarios en dos universidades mexicanas
}

El presente trabajo incorpora los significados que los académicos otorgamos a la normativa universitaria y a dejar hablar y escuchar, de acuerdo con Kaës, cómo la institución nos contiene, a la vez que sufre en nosotros. Nos interesa hacer referencia, en especial, a los mandatos que las universidades han incor-

El presente trabajo reconstruye los significados que los académicos otorgamos a la normativa universitaria y al dejar hablar, según Kaës, cómo la institución nos contiene y sufre en nosotros. Se hace referencia, en especial, a los mandatos que las universidades han incorporado a través de la validación de distintas prácticas. Desde esto, se abordan las diversas trayectorias y grupos que se instituyeron en dos casos de universidades en México: el de la formación de la Licenciatura en Pedagogía de la Universidad Autónoma de Nuevo León (UANL), y una experiencia de formación docente en el Instituto Tecnológico y de Estudios Superiores de Occidente (ITESO).

Palabras clave: innovaciones institucionales, identidades académicas, historias y cambio institucional.

- Profesora-Investigadora del Departamento de Estudios Socio-Urbanos, CUCSH, Universidad de Guadalajara.

rosmar90@gmail.com

- Profesora-Investigadora del Departamento de Psicología, Instituto Tecnológico y de Estudios Superiores de Occidente (ITESO).

ngomez@iteso.mx porado a través de la validación de distintas prácticas en las que subyacen bien procesos de organización en torno al campo de conocimiento, bien el énfasis en propuestas curriculares, así como aquellos más recientes en los que se privilegian la "alta productividad" y los consabidos criterios de eficacia y eficiencia, en los que a su vez se advierte el predominio del desarrollo burocrático, acentuando la celeridad del cambio.

El presente artículo aborda dos casos de universidades mexicanas que, si bien diferenciados espacial y temporalmente, se encuentran articulados por la reflexión acerca de la forma en que los sujetos habitan las instituciones universitarias y el lugar en el que se ubican en 
ellas. Se encuentran así experiencias grupales que conforman identidades muy fuertes de tipo comunitario, y que desde la colectividad construyen utopías que sirven como encuadre a proyectos institucionales, grupales y personales. Frente a ello, florecen actualmente otros estilos de prácticas académicas y formas de adscripción institucional en las que los proyectos diseñados desde fuera generan malestar y sufrimiento de los formadores de docentes, a raíz de los atributos (insostenibles) que de ellos se demandan.

Como se mencionó, los dos casos referidos se ubican geográfica y temporalmente en espacios y momentos distintos. No obstante, es relevante mostrar estas alteridades, así como su ubicación en el espectro nacional. La siguiente es su ubicación territorial:

\section{Ubicación geográfica}

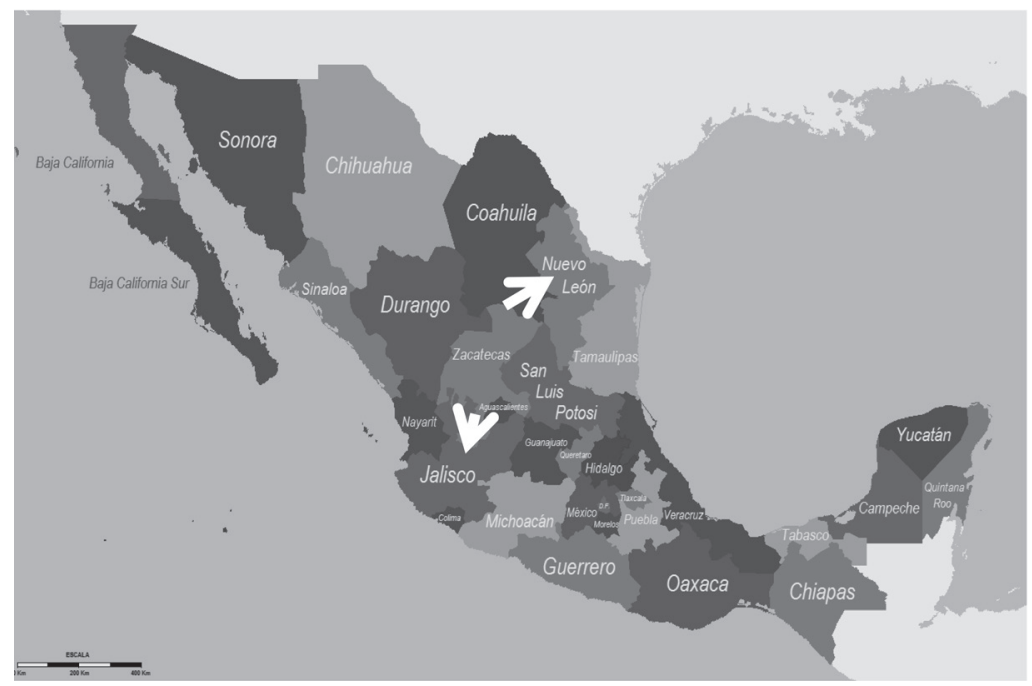

Fuente: http://www.worldmapfinder.com/Map_Search.php?ID=/Es/ North_America/Mexico\&PG $=5$ 


\section{Preguntas de investigación}

- ¿De qué forma los académicos enfrentan, desde su actoría, ${ }^{1}$ una serie de prescripciones provenientes de distintos mandatos institucionales que impactan su práctica, perfil docente y su concepción de la educación y las formas de adscripción?

- ¿Qué similitudes o diferencias es posible observar en dos casos de estudio con gran diferencia temporal y espacial?

- ¿Cómo inciden en los actores los distintos mandatos institucionales y cómo los académicos se colocan y resuelven conflictos frente a la incidencia de nuevas demandas y prácticas laborales?

- ¿Qué tipo de constructos identitarios se generan a partir de la diversificación de las prácticas académicas, los mandatos institucionales y la emergencia del conflicto?

\section{Abordaje metodológico}

La investigación se inscribe en la metodología de corte interpretativo, ya que busca recuperar los procesos de significación, comunicación y simbolización de los sujetos participantes, rescata la subjetividad y le otorga un peso importante a la interpretación. En el primero de los casos estudiados, se realizaron relatos de vida a través de entrevistas a profundidad a dieciocho informantes clave, todos ellos académicos de tiempo completo, en tanto que, para el segundo caso, fueron entrevistados treinta y seis docentes que habían terminado su proceso de formación en el Diplomado en Competencias Docentes, y se implementaron grupos de discusión con los instructores. Las divergencias

I. La actoría es la capacidad de un actor de ser sujeto social en sí mismo desde una actuación protagónica en el mundo. Para más información, se sugiere ver Crozier, M. y Friedberg, E. (1990). El actor y el sistema. Las restricciones de la acción colectiva. México: Alianza Editorial Mexicana. 
temporales y espaciales en ambos casos reafirman los procesos de creación continua que los sujetos imprimen a las instituciones que habitan y las construcciones que realizan ante distintos mandatos institucionales.

\section{Análisis comparado}

Adoptamos en el análisis de datos un pensamiento comparativo como método científico-social. Dentro de tal postura, las técnicas utilizadas "no buscan relacionar fenómenos culturales entre sí en lo que concierne a su contenido fáctico, sino que se refieren más bien a relaciones supuestas entre distintos fenómenos o niveles de sistemas" (Schriewer, 1993, p. 198). Se trata, pues, de vincular relaciones, y no hechos observables.

Otro elemento relevante de diferenciación en estos abordajes está en el énfasis que se hace con respecto a las semejanzas y las diferencias entre los casos estudiados. Así, en el caso de la comparación como operación mental, la búsqueda de semejanzas es prioritaria, mientras que en el caso de la comparación como método científico, orientada a la producción teórica, se otorga una atención particular a las diferencias empíricas. Si bien en un primer momento hubo un acercamiento a los datos desde la perspectiva de la comparación como operación mental, buscando similitudes empíricas en los casos de estudio, en el presente trabajo interesa más bien explorar la perspectiva de la comparación como método científico-social, identificando ciertamente similitudes, pero también con una disposición hacia el reconocimiento de la singularidad de cada caso, todo ello para lograr una mayor profundización y teorización de los fenómenos. Lo anterior resulta además particularmente relevante para nosotros en la medida en que nos permite, como miembros de investigación fuertemente implicados en sus propios casos, distanciarnos de la dimensión empírica de 
los datos de investigación para buscar proyectarnos hacia un trabajo de teorización.

\section{Encuadre teórico}

En este trabajo se aborda el tema de cómo los académicos van desarrollando estrategias para incluirse en las instituciones y, al mismo tiempo, cumplir los mandatos sin desconocerse como ¿actores, sujetos, docentes, personas?

Se trata, pues, de formar parte de una cultura. Para Lapassade, "instituir es hacer entrar en la cultura, la cual da acceso a las instituciones sociales" (1977, p. 311). En sentido estricto, etimológico, instituir es mantener en pie, "erguido", elaborar al individuo de acuerdo con normas; es dar forma (Lapassade, 1977, p. 312). Los profesores instituyen para poder seguir perteneciendo a la institución, pero, al mismo tiempo, para seguir siendo dueños de sus decisiones pedagógicas.

Un aporte importante de las corrientes institucionalistas francesas en torno a la institucionalización tiene que ver con la añadidura del punto de vista dialéctico a la consideración de la dinámica de lo institucional, y con la propuesta de discriminar, en la operación concreta de las instituciones -como dimensiones complementarias siempre presentes-, "lo instituido (lo fijo, lo estable) y lo instituyente (el cuestionamiento, la crítica y la propuesta opuesta o de transformación)" (Fernández, 1998a, p. 36). Entonces, lo instituido y lo instituyente se manifiestan siempre complementarios, siempre antagónicos, siempre presentes; es difícil una separación limpia entre ambas dimensiones, ya que no se localiza lo instituido sólo en el nivel vertical y lo instituyente exclusivamente en el plano horizontal. En lo instituido subsiste lo instituyente, y viceversa. En los casos que hoy nos ocupan, lo instituido se localiza prioritariamente en distintas reformas temporales y espaciales, 
pero acentuando sus implicaciones para los académicos, junto con la capacidad de nuevas creaciones en los distintos grupos y culturas académicas. Para Kaës, nos encontramos frente a la creación o recreación de nuevos vínculos, vínculos instituidos.

I. El caso de la refundación de la Licenciatura en

Pedagogía de la Universidad Autónoma de Nuevo León (UANL) ${ }^{2}$

\section{La Facultad de Filosofía, Ciencias y Letras}

Se hace una breve referencia a los periodos por los que transitó la nombrada en su fundación Facultad de Filosofía, Ciencias y Letras, hasta llegar a la ahora Facultad de Filosofía y Letras, ${ }^{3}$ toda vez que en ella surgió, en 1974, el Colegio de Pedagogía, el cual se agregó al proyecto inicial de ofrecer formación de posgrado a profesores normalistas, proyecto que, aunado a los cambios institucionales (del entorno y de la misma facultad), impulsó a los profesores que hemos llamado "refundadores" a otro tipo de discusiones académicas, que culminaron en la construcción de una licenciatura-que no de un sistema de estudios de posgrado- centrada en la discusión acerca de la conformación de un nuevo campo de conocimiento, el educativo, y las prácticas que del mismo

2. Esta reconstrucción forma parte de un trabajo previo (Romo, 2013). La Universidad Autónoma de Nuevo León, ubicada en el noreste de México, es la tercera universidad del país en cuanto a población estudiantil, después de la Universidad Nacional Autónoma de México y la Universidad de Guadalajara. Es considerada la institución pública de educación superior más importante del noreste mexicano. Con sede en el municipio de San Nicolás de los Garza, dentro del área metropolitana de Monterrey, cuenta también con diversos campus en varios municipios del estado de Nuevo León. Véase: Universidad Autónoma de Nuevo León (20I I). Recuperado de: www.uanl.mx

3. Así pues, al iniciarse el año escolar 1950-1951 (septiembre de 1950), quedó constituida la Facultad de Filosofía, Ciencias y Letras, instalándose en un edificio propio en el centro de la ciudad (De la Torre, I99।, p. 2). 
se derivan, rebasando los proyectos de formación dirigidos al magisterio normalista.

La Facultad de Filosofía, Ciencias y Letras de la entonces Universidad de Nuevo León "se creó por acuerdo del Consejo Universitario (máximo órgano de decisión de la UANL), el 21 de abril de 1950" (De la Torre, 1991, p. 1), bajo el rectorado de Raúl Rangel Frías, personaje destacado en la vida cultural y política del estado, quien había sido promotor de la "escuela de verano":

[La facultad] se crea como resultado de [...] aquella escuela de verano que se inició por el [año escolar] 45-46 y que traía a la ciudad, a través del Departamento de Acción Social [...], un departamento como de extensión, [...] a intelectuales destacados para hablar de asuntos que en general tenían que ver con la Filosofía, con la Literatura, con la Historia (entrevista personal, 14 de enero de 20I I).

Rangel Frías, además de ser abogado, fue impulsor del humanismo, en tanto que su afiliación al oficialista Partido Revolucionario Institucional lo llevó posteriormente a la gubernatura del estado. Este vínculo cultural-político marcó el nacimiento de la Facultad de Filosofía, Ciencias y Letras y su primera orientación, de corte "humanista liberal-oficialista", como lo describe otro profesor refundador:

La facultad se crea desde mi punto de vista, como proyecto del Estado [...] para atender el desarrollo de la cultura [pero en los inicios], se crea, concretamente para formar profesores para la universidad, profesores incluso del campo de las ciencias naturales, como una especie de Escuela de Altos Estudios o Escuela Normal Superior (entrevista personal, 16 de marzo de 2010).

La nominación inicial de Facultad de Filosofía, Ciencias y Letras se conservó hasta la mitad de la década de los sesenta, para transformarse posteriormente en Facultad 
de Filosofía, Letras y Psicología, ante la integración de esta última carrera, pero no ya de los estudios correspondientes al área de ciencias exactas, como lo señala Miguel de la Torre:

El nombre de Facultad de Filosofía, Ciencias y Letras y, consecuentemente, los cursos del área de las ciencias exactas orientados a la formación de docentes universitarios en ese campo, habrían de durar en nuestra institución algún tiempo; luego, y ya en el campus universitario, entre 1966 y 1973, pasará a ser la Facultad de Filosofía, Letras y Psicología, por haberse agregado a ella la carrera de Psicología (De la Torre, 1991, p. 10).

Fue en el año de 1974 cuando se transformó en la actual Facultad de Filosofía y Letras. Dicho año coincide con el periodo que hemos nominado de "refundación", vinculado a la aparición de nuevas profesiones (entre ellas la pedagogía), así como al abandono paulatino en todos los programas de estudios de la orientación hacia la formación magisterial, constituyéndose todos en licenciaturas.

\section{La refundación: 1974}

Las distintas fases en el proceso de aparición, refundación e institucionalización de la carrera de Pedagogía en la actual Universidad Autónoma de Nuevo León (UANL) muestran diversas temporalidades en las que es posible advertir formas de gestión diferenciadas.

Interesa destacar las similitudes entre el estilo de gestión y la concreción de proyectos académicos desde la perspectiva del análisis de lo institucional (Fernández, 1998b), esto es, desde el conjunto de significados bajo los cuales habitó la institución el grupo de académicos que hemos nombrado "refundadores" por su participación en el proceso de "refundación" de la Facultad de Filosofía y Letras, y en particular 
del Colegio de Pedagogía (1976-1988), en contraste con las dinámicas actuales.

El tipo de gestión apuntado se vinculó con sólidas afinidades político-académicas, toda vez que los estilos de organización y producción en dicha década estuvieron marcados por la prevalencia del trabajo grupal y la creación colectiva, lo que generó identidades grupales fuertes, de tal forma que el referente grupal y el sentido de pertenencia a este constituyeron el núcleo del movimiento institucional, lo cual fundó, a la vez, una nueva etapa en la facultad, bajo el predominio de lo académico-político-grupal. Es posible advertir estas nuevas configuraciones en el siguiente esquema:

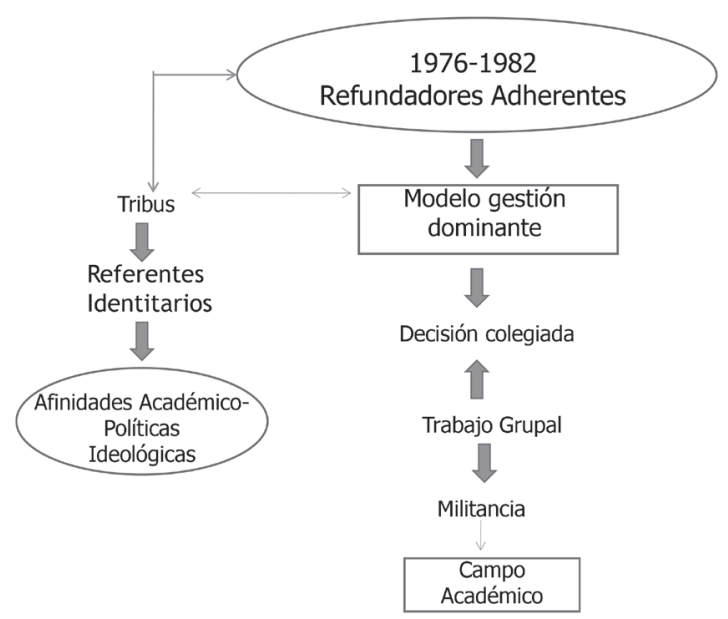

Fuente: elaboración propia a partir de las narrativas trabajadas.

Los proyectos de refundación en la Facultad de Filosofía y Letras se vincularon a propuestas que provenían de la experiencia en la militancia política de directivos y grupos de maestros en distintos grupos de izquierda, así como al acompañamiento del recién creado Sindicato de Profesores 
Universitarios. Dicho acompañamiento, aunado al activismo y "la insurgencia estudiantil", culminó en el año de 1969, con el logro de la autonomía universitaria, como lo señala uno de los exfuncionarios de la facultad y entonces militante del Partido Comunista:

En ese mismo año [1968] estalló el activismo estudiantil en la universidad, y en el 69 [se alcanzó] el logro de la autonomía. Por eso se están conmemorando acá, en actos casi privados, los 40 años [de la autonomía] porque institucionalmente no hay ni un guiño de que se quieran acordar (entrevista personal, 19 de noviembre de 2009). ${ }^{4}$

Con la agitación estudiantil de 1968 y el movimiento por la autonomía, repercusiones gubernamentales se hicieron sentir de inmediato, y en el mismo año de 1969, el Gobierno estatal, encabezado por Eduardo Elizondo, promovió la apertura de universidades privadas a través de los vínculos que mantenía con empresarios regiomontanos, aduciendo problemas presupuestales para el apoyo a la universidad pública, pero en realidad con el objeto de desarticular la congregación de alumnos y los movimientos estudiantiles en estas instituciones:

Aquí [en Monterrey] empezaron a crearse universidades privadas [...] en el 69 [se fundaron] la Universidad de Monterrey [UDM] y la Universidad Regiomontana [UR], bajo el gobierno de Eduardo Elizondo, [...] [quien] tenía ligas estrechas con la iniciativa privada (entrevista personal, 19 de noviembre de 2009).

4. En la historia oficial, se reconoce la obtención de la autonomía en el año |97|: "Para el año de 197I, diversas manifestaciones sociales obligaron al Gobierno a disminuir su injerencia en la institución y otorgarle el estatuto de autonomía aún vigente, dando paso al nombre con el cual se le conoce desde esa fecha: Universidad Autónoma de Nuevo León" (UANL, 20I I). 
Estos movimientos gestaron al interior de la Facultad de Filosofía diferentes estilos de dirección entre los nuevos "grupos" de izquierda, tales como espartaquistas ${ }^{5}$ y Concepto Estudiantil, ${ }^{6}$ frente a los otrora prevalecientes grupos conservadores en la facultad, cuya formación de origen se vinculaba a las dos carreras que predominaron desde los años cincuenta: Licenciatura en Filosofía y Licenciatura en Letras (Amores, 2009, p. 6).

Dicha apertura dinamizó la vida académica: los espacios de decisión colegiada y la impronta del trabajo grupal se instituyeron como modelos de gestión predominante, en tanto que la confrontación en el plano epistémico entre grupos fue cada vez más explícita, lo que fortaleció la vida académica, toda vez que evidenció diversas posturas, cuestionamientos y formas de abordaje de la complejidad social. La refundación de la facultad estuvo acompañada de la aparición de nuevas profesiones: Licenciatura en Historia, Pedagogía, Sociología, Lingüística Aplicada (sustituyendo a la Licenciatura en Traducción) y posteriormente la Licenciatura en Bibliotecología.

Este crecimiento respondió a la consabida demanda estudiantil que durante la década de los setenta vivieron las universidades mexicanas, pero también fue una estrategia política de los grupos de izquierda en ascenso dentro de la universidad, que fueron ocupando puestos de poder, tal y como lo señala otro exfuncionario de la Facultad de Filosofía y Letras:

5. A la pregunta expresa "¿Dentro de qué grupo militaba?", un entrevistado respondió: "Espartaquista, en el que yo andaba cerca desde la secundaria; también hice la secundaria por la noche" (entrevista personal, 20 de noviembre de 2009). 6. "Paralelamente, todo el activismo estudiantil había llevado a la creación de un organismo que se llamaba Concepto Estudiantil, en donde había mucha presencia de la juventud comunista y se había estructurado democráticamente [...] Y entonces, ahí aparece, en un momento dado como una instancia que puede representar posibilidades de promoción académica y política, la pertenencia al partido, la participación en el movimiento" (entrevista personal, 20 de noviembre de 2009). 
Se abrieron nuevas licenciaturas porque a mayor número de carreras, profesores y estudiantes, mayor era el presupuesto asignado a la facultad (entrevista personal, 29 de noviembre de 2009).

Si bien estos momentos de refundación develan enfrentamientos entre grupos, uno de los signos distintivos fue que los nuevos proyectos compartían concepciones semejantes en el plano ideológico, académico y político, en especial entre los aludidos grupos provenientes de la izquierda y los académicos extranjeros -exiliados argentinos, quienes fueron invitados a sumarse a la planta docente-, lo que favoreció nuevas discusiones académicas, con la ya descrita institucionalización del trabajo grupal y la construcción de proyectos colectivos. Los referentes grupales podemos apreciarlos a continuación:

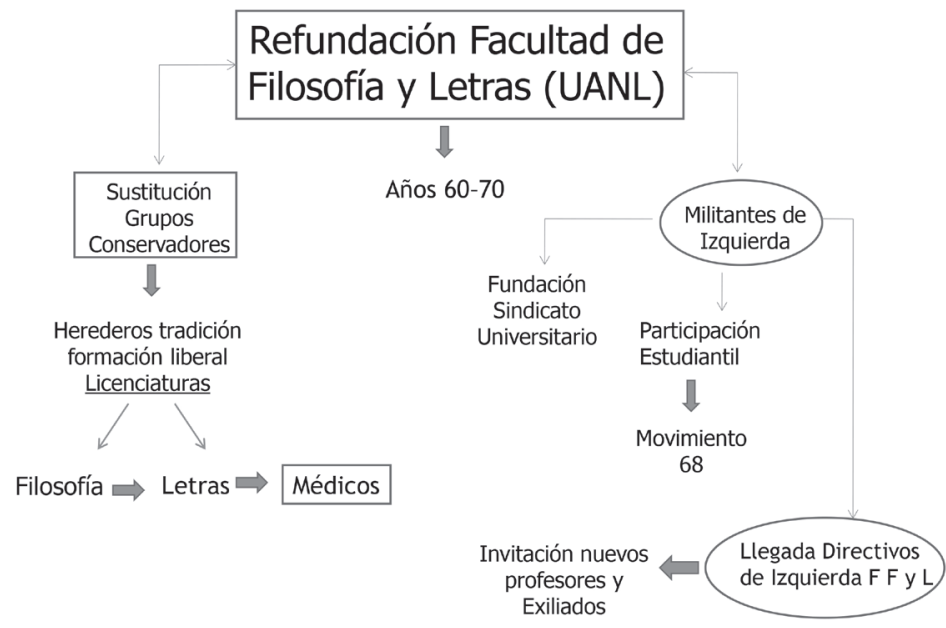

Fuente: elaboración propia a partir de las narrativas trabajadas. 


\section{Los normalistas: 1974}

El primer coordinador del Colegio de Pedagogía, egresado de la Normal Básica, con una fuerte experiencia en ese ámbito y en cargos directivos, cursó la Licenciatura en Filosofía en la misma facultad y fue apoyado políticamente por los grupos directivos de la normal en el proceso de apertura del plan de estudios en el año de 1974, y posteriormente por el grupo médico de la universidad. Dicho perfil normalista lo compartía la primera generación de estudiantes, quienes en ese momento contaban aún con formación técnica, por lo que ingresaron a la universidad con la expectativa de lograr el grado de maestría, como sucedió en otras universidades del país, ${ }^{7}$ lo que les permitiría, además de contar con posgrado, trabajar en bachilleratos y en la misma universidad.

Sin embargo, este primer proyecto no prosperó, en gran parte por el clima político que se vivía en la facultad, y también porque se trasladó en forma íntegra el plan de estudios de la Universidad Nacional Autónoma de México (UNAM), lo que hacía al programa depender de un grupo de profesores de la misma UNAM, muy ligados de igual forma al normalismo. Esto originó el primer gran cisma y el enfrentamiento académico-político e ideológico y de estilos de gestión diferenciados que aún subsiste en la licenciatura y en la misma facultad, sin posibilidad de conciliación, pero que genera temporalidades diferenciadas en el conjunto grupos-institución: "normalistas versus universitarios". ${ }^{8}$

7. Al respecto, Concepción Barrón Tirado ha documentado las disputas que este tipo de proyectos provocaron en la UNAM (con el consabido retiro de los profesores normalistas de la universidad y la independencia de esta última respecto a la Escuela Normal Superior en la Ciudad de México), y posteriormente en los estados (Barrón, 1992, p. 17).

8. Al hacer referencia a institución en este lugar, nos referimos concretamente a la Facultad de Filosofía y Letras. 


\section{Refundadores: 1976}

Es este el contexto en el que surge la refundación del Colegio de Pedagogía, ya que se integraron nuevos grupos académicos que sustituyeron, o bien convivieron, con el colectivo fundador de la carrera.

La incorporación de los profesores con adscripción a grupos de izquierda, así como la llegada de exiliados argentinos en el año de 1976, conformó un ambiente en el que la militancia se volcó al ámbito académico, además de que se privilegiaron estilos de gestión que promovieron la participación y construcción de proyectos colectivos y, aun cuando convivieron con estilos de control muy rígidos y centralizados -en especial en la figura de los directivos-, fue un período en el que se fortaleció el sentido de pertenencia, de colectividad, con una gran capacidad instituyente.

Estas formas de configuración identitaria, en las que privó la dimensión del yo-nosotros en el ámbito del trabajo remunerado, se constituyeron a través de modelos culturales y formas de organización en las que los actores se conocían o desconocían, no sólo en el ámbito laboral. Al conformar relaciones subjetivas e intrasubjetivas fuertes, estas trascendieron el ámbito del empleo, incidiendo en los estilos de implicación en el trabajo. Las formas de organización laboral y social incidieron también en los vínculos familiares y afectivos, lo que conformó un tipo de organización comunitaria (Dubar, 2002), toda vez que se compartían distintos ámbitos de la vida profesional y privada.

La noción de colectividad permitió a los actores incluirse, ser protagonistas y partícipes en la conformación y desarrollo de proyectos colectivos. Los estilos de trabajo y la concepción académica rememoran la formación de tribus, en las que los referentes identitarios condensan afinidades académico-políticas e ideológicas. 
1988-1990: la pulverización y los guiños de la globalización

A través de la historia de la carrera, es posible advertir tanto la conformación de trayectorias académicas como su reestructuración. A raíz de ello, el proyecto académico se fue rediseñando en función de nuevas experiencias y vínculos con otros grupos de trabajo externos a la institución, a manera de otro tipo de prácticas que abrían nuevas posibilidades de desarrollo profesional tanto a los refundadores como a la tercera y cuarta generación de -en ese momentojóvenes académicos: "los herederos", egresados de la carrera que se incorporaron a la planta docente durante la década de los ochenta, apoyando el desarrollo del proyecto propuesto por los refundadores. Véase entonces cómo fue avanzando la temporalidad grupo-institución:

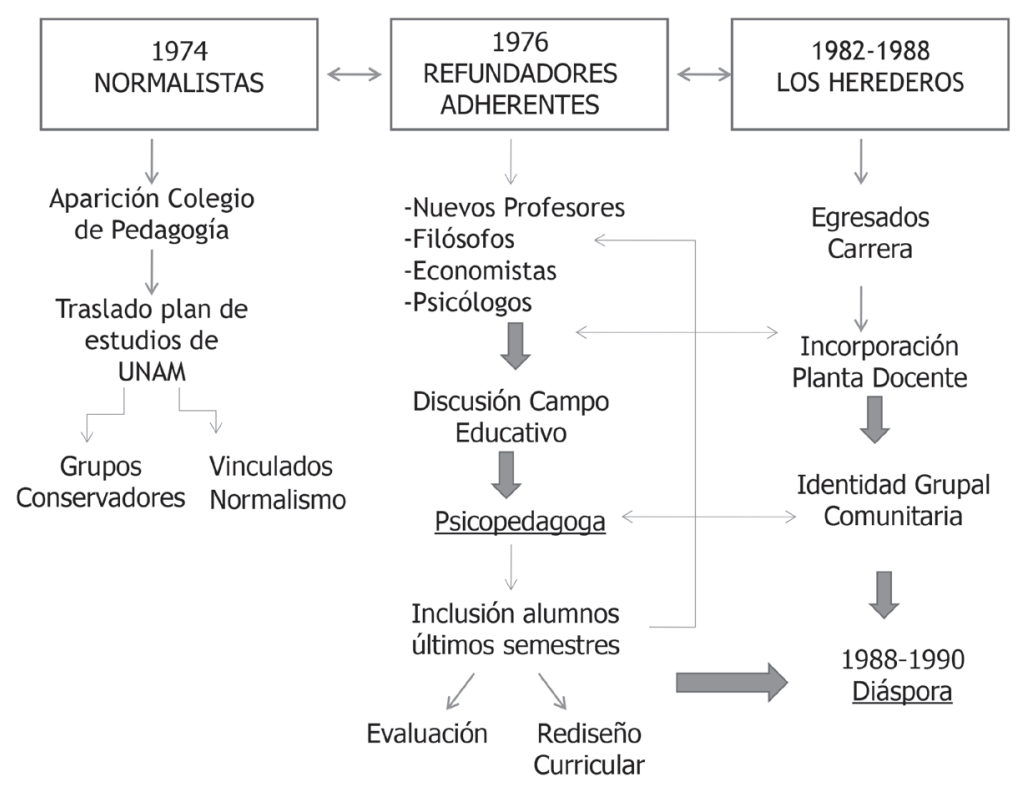

Fuente: elaboración propia a partir de las narrativas trabajadas. 
A finales de los ochenta, se produjeron fisuras al interior del colectivo, bien por elegir otras instituciones que permitieran desarrollar otro tipo de prácticas que cobraban mayor legitimidad en el mundo académico (como la investigación), bien por acceder a estudios de posgrado - maestrías y doctorados-, bien para participar en proyectos innovadores como la "Universidad Virtual”. Aunado a lo anterior, también se dieron desplazamientos por razones de tipo económico a raíz de los bajos salarios que imperaron durante dicha década en las universidades públicas mexicanas, lo que obligó a varios académicos a buscar compensaciones económicas trabajando en otras instituciones, y en especial en universidades privadas ${ }^{9}$ de reconocimiento.

La práctica académica se transformó, sujeta a los mandatos federales, al instituirse a lo largo de la década de los ochenta la planeación y ejecución de los procesos de evaluación y concursos permanentes para la obtención de recursos, lo que originó estas diásporas en las que los grupos se fragmentaron y las trayectorias académicas tomaron otros rumbos bajo la seducción de propuestas para obtener salarios mejor remunerados, abandonando o distanciándose del proyecto académico y, en ocasiones, de la institución en la que se participó.

Este proceso generó, recordando a Robin, la pulverización de las identidades, en el sentido de que no son posiciones fijas: "Esas posiciones están en movimiento y a destiempo, son los mismos los que pasan de una posición a otra permanentemente" (Robin, 1998, p. 35).

Las fisuras producidas permiten advertir temporalidades grupales e institucionales, así como referentes identitarios concretos, que en el interjuego de lo social, institucional y

9. Las cuales captaban profesores de prestigio y con experiencia, formados en universidades públicas.

\section{6}


personal encuentran su articulación desde la dimensión grupal. Véase el siguiente esquema:

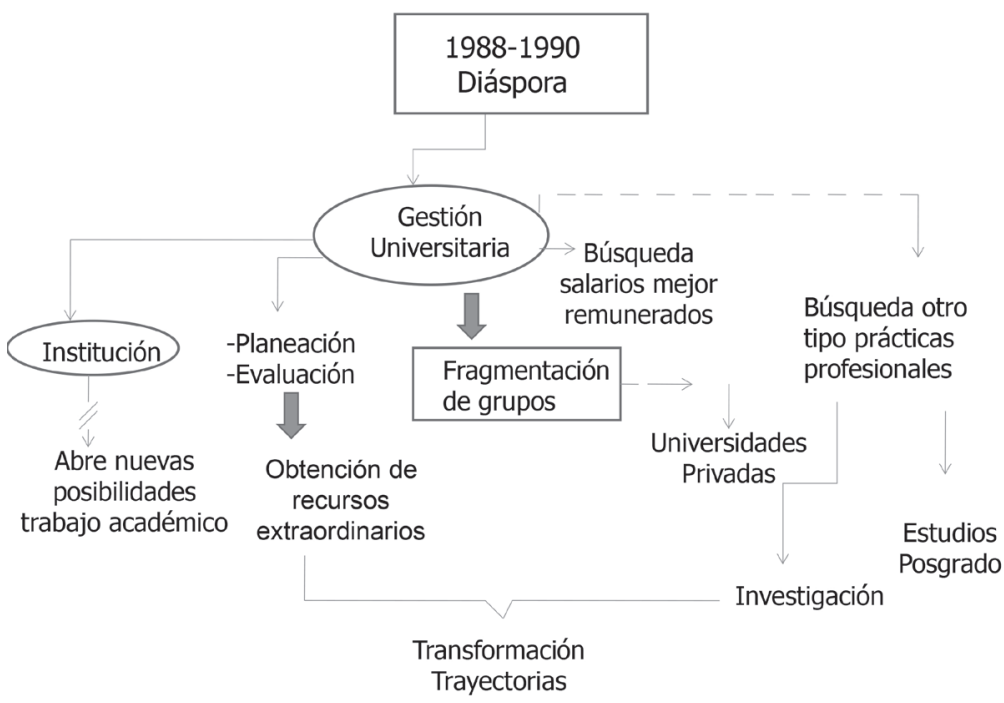

Fuente: elaboración propia a partir de las narrativas trabajadas.

A raíz de la diáspora grupal (Fernández, 2008), lo que prevalece a veinte años de distancia es un sentido de desgarramiento, de pérdida; aun cuando se cuente con otras satisfacciones, aparece la nostalgia: el "nosotros", la "comunidad que fuimos". Predomina la sensación de gran vacío en los que regresan a la institución de origen, o al lugar de refundación, y lo habitan nuevamente, pero con otro entorno: un retorno al "no lugar".

Es una doble traición: a la fundación y al origen. Es también una rebelión frente a la institución que no reconoció la dimensión humana de estos grupos refundadores, ya que, si bien aflora la capacidad de agenciamiento, esto es, de elección y decisión personal, por otra parte el hecho habla de la expulsión que generan las instituciones, como 
en el caso aludido, a través de la prevalencia de bajos salarios; la incapacidad para adecuarse a nuevas políticas de homologación de académicos, como ya se venía realizando en otras universidades públicas del país; ${ }^{10}$ la ausencia de nuevos proyectos; y el abandono de prácticas emergentes en la academia, como la investigación, que hasta la fecha ha contado con poco apoyo en la institución analizada.

Esto plantea la necesidad de seguir pensando en las dinámicas que operan institucionalmente bajo los actuales modelos de gestión en las universidades, así como en las crisis identitarias producto de los nuevos vínculos de los docentes con la institución, con los pares y con las formas del ser y hacer académico. Aflora de igual forma la temporalidad en la que los sujetos se encuentran ubicados respecto a su vida profesional, y que tiene que ver, por ejemplo, con las representaciones con las que los académicos habitan la institución en el tránsito entre la etapa de mayor productividad laboral (con trayectorias marcadas por el éxito y reconocimiento y la búsqueda de otros espacios u opciones profesionales), al paso progresivo hacia la jubilación y el retiro.

Las distintas tensiones esbozadas inciden en la configuración de identidades profesionales desde el sentido que los sujetos otorgan al trabajo, su situación laboral y su etapa de vida. Por ello, sostenemos que las trayectorias académicas se encuentran marcadas por "sismos" y fisuras, por cambios permanentes determinados a la vez por las actividades que se realizan, las relaciones de trabajo, los grupos que se constituyen, el tipo de pertenencia y reconocimiento de los pares, así como por el compromiso de los actores con las actividades desarrolladas, por lo que resulta evidente la complejidad de procesos a los que se acerca el abordaje de 
las dimensiones inter- e intrasubjetivas en la constitución identitaria.

Es posible advertir la celeridad de estos cambios a partir de la década de los ochenta, tanto en el contexto social como en el universitario. El último se evidencia en las transformaciones de los procesos institucionales regidos por nuevas políticas de planeación y evaluación de las instituciones de educación superior (IES) mexicanas y sus actores, como condición para la obtención de recursos federales, lo que modifica trayectorias, formas de organización y prácticas.

Por ello, hemos incorporado la noción de "diáspora" en la indagación de estos nuevos procesos. Dicho concepto, desde la perspectiva sociocultural, nos aporta un encuadre a través del cual es posible advertir nuevas reconfiguraciones y referentes identificatorios, los que Mireya Fernández (2008) diferencia de otro tipo de desplazamientos como la migración o el exilio. ${ }^{11}$

De ahí que se retome también la noción de "conciencia diaspórica" para referirse a estas identidades recreadas entre los grupos intelectuales, en las que, parafraseando de nuevo a Fernández, se conservan referentes de la sociedad de llegada y la cultura de la sociedad de partida, conformando una unidad cultural: "en una dinámica de negociación e intercambio entre distintos sujetos" (Fernández, 2008, p. 318), y también para referirse a un proceso en continua transformación en relación con los otros y con los cambios estructurales. Por ello, podemos considerar "las identidades culturales como puntos de identificación inestables, con procesos constantes de identificación y sutura" (Fernández, 2008, p. 318).

En el caso trabajado, los referentes de pertenencia institucional-grupal son muy claros y están marcados por

II. El origen de las migraciones es económico, en tanto que el exilio porta un origen eminentemente político. 
la permanencia institucional de los actores, lo que tiene que ver con el periodo de expansión de las universidades públicas en México a partir de la década de los setenta y con el consabido ingreso a estas de gran cantidad de nuevos profesores, la mayoría de ellos jóvenes, incluso pasantes, estudiantes de licenciatura o recién egresados. Es por ello que resulta importante recordar el trabajo de Landesmann, et al. (1996), quienes señalan este momento como el del surgimiento de un nuevo profesional en México: el académico universitario, quien, a diferencia de los catedráticos, vive de la academia y se caracteriza por la permanencia institucional: "el punto en común es su pertenencia a las instituciones educativas y su inscripción en las funciones de producción y transmisión del conocimiento y la cultura" (Landesmann, et al., 1996, p. 158).

De ahí que encontremos conformaciones identitarias y grupales tan fuertes y su progresivo avance durante la década de los ochenta hacia trayectorias y construcciones identitarias diaspóricas, determinadas por cambios contextuales, por los avances de las disciplinas y las prácticas profesionales, así como por los nuevos mandatos institucionales que han orientado el trabajo académico hacia prácticas cada vez más individualizadas.

2. A medio camino. Los formadores frente a la reforma educativa: el Instituto Tecnológico y de Estudios Superiores de Occidente (ITESO)

A partir de la década de los noventa, han sucedido una serie de reformas educativas en América Latina que se inscriben en las novedades pedagógicas de la época y se invisten de un discurso democratizador, en especial en instituciones que reivindican la gestión participativa, desde donde adquiere densidad el rescate de lo instituyente. 
Esta idealidad se decanta de distintas maneras en cada uno de los actores que protagonizan la puesta en marcha de la innovación; es decir, en estos procesos encontramos intersticios de "fosilización", pero también encontramos esfuerzos sostenidos por rescatar la dimensión instituyente como vuelco hacia lo humano.

Los docentes suelen ser el último paso de la estrategia de implementación de las reformas educativas: se les adjudica la responsabilidad de su concreción. No son pocos los estudiosos sobre el tema que vuelven su mirada hacia el maestro y el respectivo proceso de apropiación e implementación de las prescripciones pedagógicas (Díaz Barriga, 2010; Guzmán, 2005; Torres, 2000). Como constante en los resultados de estos estudios, se encuentra la afirmación de la existencia de un desencuentro entre maestros y reforma, así como la necesidad de hacer coincidir dichas políticas educativas con procesos formativos para favorecer la participación protagónica de los profesionales de la educación. Aparece en la institución a la que se hace referencia un nuevo "actor en escena": el formador.

La reforma que sirvió de referente al trabajo que ahora se presenta reivindicaba que el formar a la mayoría de profesores de bachillerato con el mismo programa favorecería la conformación de un marco curricular común.

Esta reforma tuvo como una de sus peculiaridades la inclusión de diversas universidades convocadas a la implementación de los procesos formativos. Esta doble intención colocó a las instituciones participantes, que fueron cuarenta y siete a lo largo del país, en un "lugar de malabares": se les demandó implementar una propuesta formativa diseñada por un grupo de expertos externos, con tiempos y procesos de selección, seguimiento, evaluación y certificación preestablecidos, y bajo la consigna de no modificar el contenido ni la organización. 
En estas circunstancias, el Instituto Tecnológico y de Estudios Superiores de Occidente (ITESO) ${ }^{12}$ tomó la decisión de involucrarse en esta experiencia con el análisis previo de lo abruptas que han resultado este tipo de reformas para los profesores, por lo que se planteó la intención de favorecer a los profesores en formación a través de una atención presencial y personalizada. ${ }^{13}$

Esto lleva a preguntarse sobre el formador, sobre su papel de mediador en esta historia transinstitucional, toda vez que la confluencia de diversas instituciones imprime un sello particular a los procesos de organización y, por ende, al interjuego entre lo instituido y lo instituyente. Se entiende lo instituido como aquello que aparece frente al sujeto como infranqueable, como una fuerza exterior y fija, mientras que lo instituyente alude al lugar del sujeto actor que se apropia, que cuestiona, que transforma. Ambas dimensiones siempre son complementarias, siempre son antagónicas y siempre están presentes en la relación entre la institución y el sujeto.

Las circunstancias en que el formador inscribió su actuación en la mencionada reforma resultaron un campo minado: muchos maestros en formación ${ }^{14}$ no tenían computadora en casa y los cursos se diseñaron en modalidad semipresencial; otros tantos no manejaban las mínimas herramientas para el trabajo virtual. Un buen porcentaje de maestros vivió como imposición la formación; algunos más no tenían información sobre la reforma, ni sobre el proceso formativo; el pago a los formadores se retardaba hasta seis meses; y existía la amenaza de que si los maestros no concluían el

12. Universidad privada ubicada en la ciudad de Guadalajara, Jalisco, en el occidente de México. Su orientación jesuítica la hace aparecer como institución humanista. 13. Toda vez que el programa se diseñó bajo la modalidad de enseñanza virtual. 14. Cabe aclarar que se incorporaron al programa de formación profesores de bachillerato de diferentes subsistemas del país. 
proceso, pagarían el costo del diplomado o podrían perder el empleo.

El formador tenía un doble mandato: cumplir con los requerimientos formales de la reforma y centrarse en la persona del profesor. Favorecer la construcción de sentido y movilizar la actoría, demanda personificada en la institución contratante, el ITESO.

Lidia Fernández abona al análisis del aumento de inseguridad e incertidumbre en las estructuraciones institucionales:

El monto de la tensión y el sufrimiento variarán, por una parte, de acuerdo con el margen de articulación con las diferencias que permiten los modelos pedagógicos operantes $y$, por otra, de acuerdo o en relación con el grado de legitimación y con el valor que dan a los resultados de la formación los mismos sujetos que sufren la violencia de algunas de sus necesidades, rasgos y deseos (Fernández, 1998a, p. 94).

A continuación se muestran tres figuras con que los formadores hacen alusión al lugar en que se colocan y la manera en que recrean la experiencia para hacer frente a la incertidumbre y así seguir adelante con la encomienda institucional, es decir, se expone el despliegue de lo instituyente. Dichas evidencias son producto de la implementación de grupos de discusión donde participó el grupo de formadores, quienes señalaron haber vivido el proceso de acompañamiento a los docentes en la oscilación entre la incertidumbre, la expectación de los resultados, la esperanza de notar cambios de actitud en los profesores, el reconocimiento de la distancia entre la idealidad y la realidad, y la empatía con los docentes ante situaciones difíciles. Se privilegió a lo largo del proceso reseñado la negociación como medida de sobrevivencia. El formador desarrolla su labor a la mitad del camino: tiene que buscar un equilibrio constante entre cumplir el mandato transinstitucional y, al mismo tiempo, 
parecerse a sí mismo: "el sujeto se ve apresado entre el deseo de satisfacer sus fines y el renunciamiento necesario para que el conjunto pueda funcionar" (Kaës, 2005, p. 62).

Los tres lugares predominantes que mencionaron los formadores para colocar su actoría fueron los que a continuación se plantean:

1) Vendedores de sueños. Véase el relato de un formador: "Era como convertir a los maestros en apóstoles de las competencias" (entrevista personal, 22 de junio de 2011). El desconcierto, que aparece constantemente en los discursos de los formadores, es desesperanza que en muchas ocasiones proviene del desaliento de los docentes. Es posible advertir en el conjunto de profesores en formación una serie de desacuerdos respecto a la implementación de la mencionada reforma, lo que origina que los formadores vivan la consigna de buscar espacios para movilizar la esperanza, para convencer a los maestros en formación de las bondades que la reforma ofrece para la mejoría de su práctica, descentrándose del sufrimiento que les genera la participación en un proceso plagado de deficiencias.

2) Ser agente de cambio. Otra posición que aparece frecuentemente en la voz de los formadores es la referida a la promoción del cambio, lo que se concreta en expresiones como la promoción "del cambio de actitudes", mostrándose en tres modalidades:

a) Menciona un formador: "los maestros llegan con la espada desenvainada, llegan enojados, llegan apáticos, llegan cerrados [...] y hay que tratar de que cambien de actitudes" (entrevista personal, 22 de junio de 2011).

b) Estos enunciados conjugan el sufrimiento compartido por todos los actores ante propuestas ajenas a quienes 
las construyen, las ejecutan y sobre quienes recaen, al tiempo que advierten los desafíos que enfrentan los formadores para avanzar.

c) Dice un formador: "ya en el camino, los maestros fueron cambiando de actitudes" (entrevista personal, 22 de junio de 2011). Esto le adjudica un papel protagónico durante el proceso al formador, ligado al cambio de lugar de los destinatarios, docentes en proceso de formación. Esta modalidad, pues, tiene que ver con dicho proceso del cambio de actitud.

En torno a los resultados, reflexiona el formador: "al final, logré que cambiaran de actitud" (entrevista personal, 22 de junio de 2011), bien cuestionando su práctica cotidiana, planteando alternativas al quehacer educativo o implementando cambios en la docencia.

3) Ser empático. Este apartado tiene que ver con el equilibrio del formador entre cumplir con lo demandado por las instituciones contratantes y simultáneamente atender a la persona, al profesor en formación.

Se encuentran tres acepciones:

a) Escucha activa para entender las circunstancias no favorables en las que el docente en formación se inscribe en el proceso. Entender la realidad en la que dichos maestros laboran y las dificultades que manifiestan para poner en práctica las innovaciones que la reforma demanda.

b) La identificación con el malestar de los profesores frente a la imposición.

c) Delimitación de la empatía. Los formadores mencionaron no poder limitarse a una relación de afecto y cercanía, lo que los orientó a buscar estrategias a fin de que los docentes en formación siguieran adelante, aprobaran el diplomado y lograran la certificación, a 
pesar de las circunstancias desfavorables en que se insertaron al proceso.

Por ello, se sostiene que las prácticas de los formadores sugieren posturas de "actoría", lo que, recordando a Kaës (2005), se desarrolla entre el ser actor, actuado y espectador. Esto es: existieron situaciones en las que era imposible la intervención de los académicos ante un programa diseñado externamente, situación que los colocó en situación de actuados. A la vez, convivían en un contexto laboral en el que se les contrató para ejecutar el programa, lo que los colocó en situación de espectadores. Pero, se advierte a la vez, requirieron de la búsqueda de resquicios de innovación y creatividad, asociada a la esperanza, al diseño de estrategias, esto es, a procesos de actoría, en un juego constante entre escenificar a un personaje y parecerse a sí mismos, es decir, ser actores.

La negociación constante y la búsqueda de equilibrio entre los mandatos y la empatía colorean de manera particular la práctica de los formadores, búsqueda como estrategia por contener la angustia, el miedo, la frustración; marcan el ser y hacer de los nuevos formadores: transformar las prácticas para no caer en la fatalidad, en la inmovilidad frente a restricciones impuestas por el exterior, así como cumplir con el mandato institucional para poder ser recontratados.

Se asiste a la constitución de innovaciones, de procesos instituyentes, a través de dinámicas en las que emerge la actoría desde la creatividad. En estas nuevas prácticas se avanza en sentido contrario al primer caso descrito en cuanto a las configuraciones identitarias. Se puede advertir aquí el progreso desde identidades dispersas a través de una contratación temporal para el desarrollo de una tarea y la conformación de grupos y relaciones de afinidad para concretar el trabajo. Aparece un tipo de conformación grupal 
sostenido por una tarea común a realizar en periodos cortos de tiempo, en la que la incidencia de los actores es ocasional.

Desde la lógica trabajada por Dubar, esto nos acercaría al "modelo afinatario", caracterizado por identidades inciertas, marcadas por el individualismo, en las que las nuevas formas de contratación son efímeras, y que se establece a través de redes de afinidad, por lo que el mismo Dubar las señala como relaciones centradas en lo afectivo, en las que prevalece la "precariedad identificante" dentro del medio profesional (Dubar, 2002, pp. 113-150), en contraste con las identidades de tipo comunitario.

Estos movimientos permiten advertir en los nuevos estilos de gestión y situación profesional la irrupción de nuevas formas de trabajo, vinculadas a proyectos externos, desconocidos para los actores y la institución, en las que se construyen procesos de actoría e innovación in situ, y que desde las pulsiones de muerte promueven nuevas creaciones.

Un reto de las instituciones educativas es no quedarse al margen de la política educativa, pero ¿cómo incorporar estos nuevos mandatos rescatando a la persona? ¿Cómo se van gestando nuevos tipos de prácticas en la perspectiva protagónica de estos procesos? Las expresiones instituyentes inyectan vida a los proyectos y reconfiguran identidades al incorporar la voz de los otros. Las reformas educativas, en su implementación, generan rupturas y desgarramientos en muchos de los actores involucrados al encontrarse frente a una nueva experiencia, lo que deja a muchos aparentemente en el vacío, pero, aunque las reformas educativas sean en muchas ocasiones "campos minados", también son espacios de personas con capacidad de actoría.

Los desencuentros entre los académicos frente a estas nuevas prácticas afrontan esfuerzos sostenidos desde lo instituido, por lo que es posible advertir un doble movimiento: las estrategias para convencer, la demanda de obediencia, 
contrapuestas con el accionar de actores erigidos como fuerza instituyente, que pelean por sostener el espacio laboral y la pertenencia. Estas polaridades tienen lugar en procesos de recreación, de resignificación y de identificación.

En cada uno de los casos trabajados se advierte la capacidad de actoría de los sujetos frente a lo instituido, así como la búsqueda de la construcción de sentido, por el resguardo de la identidad.

Los diversos mandatos que van coloreando la vida institucional toman densidad desde el acercamiento a las temporalidades; editan de diversas maneras la forma en que los académicos habitan y transforman las universidades en el interjuego entre lo instituido y lo instituyente, entre ser actor, actuado y espectador al mismo tiempo.

En el interjuego entre lo instituido y lo instituyente se van gestando nuevos tipos de prácticas y de agrupaciones, lo que permite mantener vivos los proyectos, las instituciones y a quienes las habitan. Lo instituyente, al ser atravesado por la colectividad, favorece a su vez la constitución de identidades colectivas, donde el eco de la voz de la otredad se va formando, no sin rupturas, no sin desgarramientos, con su interior teñido por el rescate de lo humano. Un proyecto vive al irse modificando, al convivir con sesgos y diferencias en los que también se generan procesos de institucionalización. Al tiempo que existen silencios, complicidades, lealtades como estrategias de sobrevivencia, se buscan intersticios de acción instituyente. Desde lo instituyente se van constituyendo nuevas institucionalizaciones.

\section{Aportes de esta investigación a las interrogantes iniciales}

En el caso de la Facultad de Filosofía y Letras de la UANL, la producción de excelencia e innovación durante la última mitad de los setenta y los ochenta se centró en el diseño colectivo de proyectos (cuyo referente se encuentra en la

\section{8}


discusión permanente respecto a la constitución de nuevos campos de conocimiento, como el educativo), y la concreción de estas discusiones en nuevas propuestas curriculares. El modelo de trabajo en la facultad y en el grupo académico con el que se trabajó fue la decisión colegiada, el trabajo grupal, acompañado de un sentido de pertenencia muy fuerte, vinculado a su vez a la pertenencia a grupos de izquierda, por lo que el trabajo académico adquiere el cariz de militancia. Recordando de nuevo a Dubar (2002), se ha localizado este tipo de identificaciones como comunitarias, toda vez que traspasa el ámbito institucional y permea las dimensiones de convivencia personal y familiar.

Los nuevos mandatos institucionales renuevan fidelidades y acomodos, reorganizan a los sujetos desde afiliaciones y hacen que se inauguren otros lugares en la institución. Los cambios, las prescripciones innovadoras, los diferentes mandatos traen consigo la reconfiguración de identidades, en un triple movimiento entre la deconstrucción, reconstrucción y construcción de referentes identitarios. De igual forma, tienen lugar novedosas formas de interacción, códigos emergentes, cambios en las representaciones de la profesión, de la institución y del lugar ocupado.

Esta movilidad influye en la manera de habitar el espacio institucional, en las trayectorias que van perfilando nuevos caminos, no sin desencuentros. Desde ahí adquiere complejidad el planteamiento respecto a la existencia de diferenciales de actoría.

El segundo caso planteado, el ITESO, resulta paradigmático, ya que representa a un nuevo grupo de "académicos formadores", en los que la pertenencia institucional no es estable y los modelos de formación vienen diseñados del exterior, y que, a través de las tecnologías e información y comunicación, provoca la reconversión del trabajo de estos nuevos docentes, lo que evidencia formaciones identitarias inéditas, enfrentadas a la individualización de las situacio- 
nes y tareas a resolver en el momento a partir de formas alternas de gestión institucional, en las que los proyectos formativos son diseñados externamente.

Si bien, en los años ochenta, Delamont (1985) analizó los problemas de la práctica docente, subrayando las interferencias en ella y diciendo que el académico tendría que mantener el control del grupo a través de la demostración del dominio de un contenido en un ambiente de aislamiento y autonomía dentro un salón de clases, se advierten ahora los cambios, toda vez que estas prácticas pierden su carácter privado, pasando a la esfera de lo público-externo y anónimo, y son puestas en marcha a través de las tecnologías de la información y la comunicación, lo que coloca a los formadores como transmisores de proyectos desconocidos, por lo que se sostiene que el "sufrimiento institucional" de los nuevos académicos se ve ahora acentuado, ya que deben crear en el momento dispositivos para resolver problemas in situ. Las prácticas se diversifican, los referentes son múltiples y cambiantes, la innovación requiere la conformación de nuevos constructos identitarios, donde la tarea de transmisión se vuelque en uno de los aspectos más importantes de la práctica magisterial.

Desparecen así los constructos identitarios inscritos en la continuidad o las identidades colectivas de tipo comunitario, ya que al modificarse el sentido que se le atribuye al trabajo como componente de la identidad profesional, los significados se transforman, al igual que el tipo de prácticas y las formas de adscripción institucional, por lo que la noción de diáspora, trabajada desde los estudios socioculturales, proporciona elementos para continuar analizando estos procesos.

Otra dimensión que resulta interesante destacar en estos procesos de innovación, aun en situaciones críticas, es la fuerza instituyente, a través de la cual los actores imprimen otro rumbo como respuesta para no quedar presos de las

\section{0}


innovaciones o los discursos democratizadores sostenidos en nuevas prácticas que llegan a los sujetos investidos de verticalidad. La demanda instituida es cada vez más compleja, propuesta como un nuevo modelo curricular, una modalidad formativa en la que no están socializados ni formadores ni sujetos en formación con la mediación tecnológica y la construcción del proyecto.

Los diversos modelos académicos a los que se ha hecho referencia se encuentran atravesados por historias discontinuas que van de los años ochenta a la actualidad. Con todas las diferencias señaladas, conservan como rasgo común el ser proyectos gestados en los intersticios de actoría, de apropiación, de resignificación, antecedidos por la búsqueda de asideros por parte de los sujetos que habitan las instituciones educativas. Aun en situaciones de "precariedad identificatoria" con la institución, se observa la búsqueda de autoría y el esfuerzo por encontrar vínculos, relaciones y producción de sentido para las prácticas desarrolladas.

Aun cuando en el segundo caso planteado se encontraron proyectos desprovistos de sujeto, también es cierto que en el momento en el que el actor se identifica con y logra decodificar "el proyecto" desde su capacidad de actoría, se generan innovaciones, incluso cuando subsisten otro tipo de respuestas ligadas al abandono, al desencuentro, a la simulación, tensiones visibles en los grupos con nuevas formas de adscripción institucional inscritas en la flexibilidad y los contratos efímeros, pero también en los otrora grupos cohesionados por el interés en lo colectivo de las discusiones disciplinares, quienes ahora se ven enfrentados a nuevas prácticas de las instituciones y formas de organización y trasmisión de conocimiento, por lo que abordar estas nuevas construcciones desde el encuadre de las conformación de conciencias diaspóricas abre otras posibilidades de indagación. 
El tema sobre las prácticas emergentes, como su nivel y discurso innovador, su destiempo, la difícil relación entre lo vertical y lo horizontal, la búsqueda de equilibrio por parte de los actores entre lo instituido y lo instituyente, el centralismo de las mismas, su endogamia o dispersión son lugares de abordaje diversos, donde no todo está dicho.

Fecha de recepción: 30 de octubre de 2014 Fecha de aceptación: 05 de junio de 2015

Bibliografía

Amores, J. E. (2009). “Don Federico Gómez en la Universidad". Interfolia. Órgano Bimestral de la Capilla Alfonsina, Biblioteca Universitaria. Nueva Época, (2), 20-22.

Barrón Tirado, C. (1992). "Reflexiones en torno a las tendencias en la formación del pedagogo". Perfiles Educativos, (57-58), I6-2I.

Bernstein, B. (1993). La estructura del discurso pedagógico. España: Morata.

Díaz-Barriga, F. (2010). "Los profesores ante las innovaciones curriculares”. Revista Iberoamericana de Educación Superior (RIES), I (I), 37-57.

Dubar, C. (2002). La crisis de las identidades. La interpretación de una mutación. Barcelona: Ediciones Bellaterra.

Fernández, L. (1998a). El análisis de lo institucional en la escuela: un aporte a la formación autogestionaria para el uso de los enfoques institucionales. Notas teóricas. Buenos Aires: Paidós.

(1998b). Instituciones educativas. Dinámicas institucionales en situaciones críticas. Buenos Aires: Paidós.

Fernández, M. M. (2008). "Diáspora: la complejidad de un término”. Revista Venezolana de Análisis de Coyuntura, I4(2), 305-326.

Gómez, N. (22 de junio de 20l I). Entrevista personal en grupo de apoyo a HJ. Guadalajara, México. 
Guzmán, C. (2005). "Reformas educativas en América Bibliografía Latina: un análisis crítico". Revista Iberoamericana de Educación, 7(5), 28-40.

Landesmann, M. y García Salord, S. (1996). Sujetos de la educación y formación docente. México: COMIE.

Kaës, R. (2005). Sufrimiento y psicopatología de los vínculos institucionales: elementos de la práctica psicoanalítica en institución. Buenos Aires: Paidós.

Robin, R. (1998). Identidad, memoria y relato. La imposible narración de sí mismo. Buenos Aires: UBA.

Romo, R. M. (I 9 de noviembre de 2009). Entrevista personal a JHT. Monterrey, México.

(20 de noviembre de 2009). Entrevista personal a MT. Monterrey, México.

(29 de noviembre de 2009). Entrevista personal a TGV. Monterrey, México.

- (16 de marzo de 2010). Entrevista personal a Mariano Avilés (pseudónimo). Monterrey, México.

(14 de enero de 20II). Entrevista personal a Mariano Avilés (pseudónimo). Monterrey, México. (20I3). "Trayectorias y cambios identitarios en dos grupos académicos: refundadores y herederos del Colegio de Pedagogía. Universidad Autónoma de Nuevo León (1970-1990)”. CPU-e Revista de Investigación Educativa, (I7). Recuperado de: http://revistas.uv.mx/ index.php/cpue/index

Schriewer, J. (1993). "El método comparativo y la necesidad de externalización: criterios metodológicos y conceptos sociológicos", en Schriewer, J. y Pedro, F., Manual de educación comparada. Vol II. Teoría, investigaciones perspectivas (pp. 236-26I). Barcelona: Promociones y Publicaciones Universitarias.

Torres, R. M. (2000). "Reformas educativas, docentes y organizaciones docentes en América Latina y el Caribe", en Torres, R. M., Los docentes protagonistas del cambio 
Bibliografía educativo (pp. 44-68). Bogotá: AB/Editorial Magisterio Nacional.

UANL (20I I). Universidad Autónoma de Nuevo León. Recuperado de: www.uanl.mx 